\title{
A COMMUNITY APPROACH TO PALLIATIVE CARE: EMBRACING INDIGENOUS CONCEPTS AND PRACTICES IN A HOSPICE SETTING
}

\author{
MARGARET COTTLE \\ CATHERINE HUGHES \\ HELEN GREMILLION \\ Unitec Institute of Technology, Auckland, New Zealand
}

\begin{abstract}
This article documents a community approach to palliative care that took place in Auckland, Aotearoa New Zealand in 2010. It is based on a case study of a 24-yearold woman of Māori and Samoan heritage. While the hospice organization that coordinated the care under discussion ordinarily engages a wide range of social work, medical, nursing, and family services, in this case a broader and participatory level of community engagement was brought to bear on the process of death and dying. In particular, the Māori concept and practice of whanaungatanga-or relational belonging though kinship, shared experience, and/or work—was taken up actively. Implications for ecosystems theory, and for engaging minority cultural groups in processes of palliative care internationally, are considered.
\end{abstract}

Drawing on a case study, this article describes some of the unique philosophies and practices of a hospice in Auckland, Aotearoa New Zealand whose staff aspire to work collaboratively and multi-systemically with their clients. ${ }^{1}$ Community-based palliative care work is particularly important for Māori, the indigenous people of Aotearoa New Zealand, and for Pacific peoples, because these cultural groups often prefer to care for a dying family member in their home. The hospice-here given the pseudonym Outreach Care to preserve confidentiality for the case discussedserves an area with a large Māori and Pacific Island population. Hospice-based palliative care internationally aspires to engage a range of community services and approaches. However, in practice, the work is often dominated by a medical model that can individualize experiences of death and dying. Mackelprang and Mackelprang (2005) argue that social workers can ensure a broader perspective is taken

\footnotetext{
${ }^{1}$ Some of the case study information and ideas in this article were presented at the 19th Hospice Palliative Care Conference in Wellington. See Hughes, Fleming, Cottle, and Davis (2010).

Address correspondence to Catherine Hughes, Unitec Institute of Technology, Private Bag 92025, Auckland, New Zealand. E-mail: chughes2@unitec.ac.nz
} 
around end of life processes and decisions, rather than a narrow view of medical issues only. Outreach Care endeavors fully to integrate ecosystemic social work into its practices. In addition, we suggest that the case study reviewed here extends beyond the typical purview of ecosystemic care by locating Māori concepts and practices as a central element of care, in ways that significantly transformed the work of the hospice. In the conclusion of this article, we reflect on implications for palliative care in other social contexts.

\section{AUTHOR POSITIONS}

Two of the authors, Cottle and Hughes, have been staff members at Outreach Care, and worked directly with the client and family discussed in this article. They also bring strongly relevant personal experience to their work: Hughes is a survivor of invasive breast cancer, and Cottle currently lives with a diagnosis of chronic lymphoblastic leukemia and does not expect to survive. Gremillion, the third author, has helped contextualize some of the theory presented in this article.

Hughes is Scottish European and a first generation Aotearoa New Zealander who is a professional social worker/academic. Gremillion is a White American immigrant to Aotearoa New Zealand and is trained as a cultural anthropologist. Cottle, a nurse, is part of a family who has been in Aotearoa New Zealand for many generations. Her original ancestors were English immigrants, and there is also Māori (Ngā Puhi) ${ }^{2}$ ancestry in her family. She is seen by others as Māori.

To a significant extent, our current cultural and social class locations are aligned with dominant discourses that are often privileged in hospice care. In this article, we challenge these discourses, documenting a process of partnership with indigenous groups that created a unique way of working within palliative care. While the approach we describe is distinctive for palliative care, we acknowledge that Māori cultural processes referred to in this article are widely used in many other social contexts in Aotearoa New Zealand. We recognize the dangers that arise from any representations of minority cultural norms and practices that come from dominant cultural locations, and we hope we are clear in our focus on creating spaces for alternative ways of working within a (relatively) socially powerful arena. Our representations of Māori concepts and ways of being are not presented for their own sake, but rather to illuminate a need for change in the makeup and delivery of hospice care in Aotearoa New Zealand.

\section{PALLIATIVE CARE}

Palliative care is defined in the New Zealand Palliative Care Strategy (Ministry of Health, 2001, p. 2) as follows:

${ }^{2} \mathrm{Ngā}$ Puhi is one of the Northern iwi (tribes) in Aotearoa New Zealand. 
Palliative care is the total care of people who are dying from active, progressive diseases or other conditions when curative or disease-modifying treatment has come to an end. Palliative care services are generally provided by a multidisciplinary team that works with the person who is dying and their family or whanau [a Māori term for extended family]. ${ }^{3}$ Palliative Care:

- Affirms life and regards dying as a normal process

- Aims neither to hasten nor to postpone death

- Aims to provide relief from distressing symptoms

- Integrates physical (tinana), social (whanau), emotional (hinengaro), and spiritual (wairua) aspects of care to help the dying person and their family/whanau attain an acceptable quality of life

- Offers help to the family/whanau/carers during the person's illness and their bereavement

The above definition draws significantly on Durie's (2001) model of health and well-being for Māori that applies these concepts to all areas of health. Durie refers to the Whare Tapa Wha Model of Māori health, which includes four dimensions: taha wairua (spiritual), taha hinengaro (mental), taha tinana (physical), and taha whanau (extended family). This view of health, as a four-sided construct, is compared to the four walls of a house, whereby all four dimensions (walls) are required to maintain stability. In a similar manner, von Gunten (2002) provides a description of the holistic nature of palliative care when he describes the four domains of palliative care as being physical, psychological, spiritual, and social (family).

Timely access to palliative care services is an issue raised by a number of authors (Carter, McKinlay, Scott, Wise, \& Mcleod, 2002; Finlay et al., 2002; Heilig, 2003; Massarotto, Carter, MacLeod, \& Donaldson, 2000; Murray, Grant, Grant, \& Kendall, 2005). In America, only 20-30\% of people who are dying are receiving hospice services (Heilig, 2003), and as we discuss below, minority cultural groups in particular often do not access palliative care. We note that the New Zealand Palliative Care Strategy (Ministry of Health, 2001, p. vii) contains the following vision statement: "All people who are dying and their family/whanau who could benefit from palliative care, have timely access to quality palliative care services that are culturally appropriate and are provided in a coordinated way." Twelve years on, we still have some way to go to achieve this vision.

\section{OUTREACH CARE}

Outreach Care is a nonresidential, community-based hospice organization providing services through two teams: family (social work) services and nursing. 
Representatives of both teams attend the initial meeting with clients and families. Such interdisciplinary collaboration is rare in Aotearoa New Zealand: currently only $25 \%$ of hospice services in the country employ social work staff, and those that do typically do not engage social work services as part of initial assessments with families (Naylor, 2012).

The nursing team at Outreach Care is comprised of enrolled and registered nurses as well as clinical nurse specialists, and the family services team includes massage and art therapists, social workers, counselors, and individuals who provide spiritual/ religious support services. While the nursing team works primarily with the dying person, the family services team works more broadly with the patient and family members and also provides bereavement support for those who have lost a loved one. The nurses also make a post bereavement visit to the family as soon as appropriate following death. Patients referred to Outreach Care have a diagnosis of a life-limiting illness, have been aged between 17 and 100, and have a predicted life expectancy of six months or less.

The theoretical underpinnings of the work at Outreach Care include an ecological perspective (Germain, 1991). By drawing on a broad systemic approach to end-oflife care, Outreach Care attempts to provide a holistic care package to the whole family as opposed to focusing on the individual person who is dying. A social systems framework allows culture to be fully acknowledged and explored, which is an important consideration in light of the large number of people who belong to ethnic minority groups in Outreach Care's catchment area. ${ }^{4}$

\section{MĀORI AND PACIFIC REFERRALS TO AND UPTAKE OF PALLIATIVE CARE SERVICES}

Although Outreach Care serves a range of cultural groups, Māori cultural processes are prioritized, in keeping with an abiding commitment in Aotearoa New Zealand to the Treaty of Waitangi. ${ }^{5}$ This treaty, signed in 1840 by representatives of the British Crown and Māori Chiefs representing the indigenous tribes, defines Aotearoa New Zealand as a bicultural nation. A commitment to it endeavors to ensure that the needs of indigenous people are paramount in the provision of health and welfare services.

\footnotetext{
${ }^{4}$ The most recent census data indicates the following population breakdown: 59\% European, 16\% Asian, 13\% Māori, 15\% Pacific peoples, 2\% Middle Eastern, Latin American, and African peoples, $8 \%$ "Other," which also consisted of people who identified as New Zealanders (Statistics New Zealand Census, 2006). The number of people who identify as European is $8 \%$ lower than the national average, and the number of Pacific people is twice the national average.

${ }^{5}$ In this paper we focus on Māori concepts and practices, although Pacific concepts and practices were also taken up in the case study we detail (there is not space to elaborate on the latter). Some practices were agreed to by community members from both cultural groups.
} 
However, for both Māori and Pacific people, disparities and inequalities in health care provision remain and are well-documented (Finau \& Tukuitonga, 1999; Reid $\&$ Robson, 2007). The National Health Needs Assessment for Palliative Care consultation document (Naylor, 2012) indicates that there is a lack of culturally safe and competent allied health care staff currently working in Aotearoa New Zealand hospices. This problem is particularly significant for Māori and Pacific people, considering the fact that they have the highest number of deaths in the 0-19 age group as well as within the 40-60 age bracket (Naylor, 2012).

Outreach Care often receives very late referrals for Māori and Pacific clients, who are often in their last few days, or even hours, of life when they are referred. Note that although Māori and Pacific people make up 28\% of the population of the catchment area served by Outreach Care, they make up approximately $80 \%$ of the patient/client population. However, there is a low uptake rate of all hospice services by Māori and Pacific families. The same is true of Asian peoples in the area: a very low number of referrals are received, even lower than that for Māori and Pacific people. This pattern reinforces the notion that hospice is regarded by these groups as a predominantly White/European middle-class institution provided for White middle-class patients. This is a statement we (authors Cottle and Hughes) have heard many times while working in the field of palliative care. It is also reinforced by what Cort (2004) refers to as "cultural mistrust," which he explains as a perceived level of discrimination of minority populations by the wider society. Cort focuses on the low uptake of hospice services by African Americans and although he states that this phenomenon may be peculiar to African Americans, we see a similar pattern in relation to Māori and also Pacific people.

There is very little published research on the latter. An exception is Bellamy and Gott (2013), who state that the goal of hospice and palliative care services meeting the needs of diverse groups in Aotearoa New Zealand is hampered by the perception of hospice as an unwelcoming environment by non-White ethnic groups. Related international literature is instructive on this point. Cort (2004) suggests that the reluctance of African Americans to engage with hospice may be indicative of its embeddedness within the health system and the legacy of many indigenous populations feeling discriminated against by that health system and by health professionals. This issue in relation to African American populations is also noted by Pullis (2011), who argues that although perceptions of hospice care have improved in older African Americans, there is still a lower rate of engagement and barriers still clearly exist. Karim, Bailey, and Tunna (2000) examined the issue of perceived underutilization of hospice services by non-White ethnic groups in Birmingham, by reviewing doctors' referral rates and beliefs about hospice care for these population groups. Their findings indicate that general practitioners and hospital consultants are less likely to refer people of ethnic minority groups to hospice. One reason for this low referral rate is that doctors are aware that hospice staff are predominantly White, and they have concerns that language differences and a lack of understanding of culture may lead to more barriers for these groups. 
Another reason is that many ethnic groups prefer to care for their own family members at home and believe that agreeing to in-patient care would constitute a failure on the part of the extended family.

Many patients we have encountered through Outreach Care believe that hospice care consists only of inpatient residential care, and this belief is a barrier to the uptake of services. Non-White ethnic groups do, however, accept home care services when these are offered as this form of care seems to be viewed as supporting their wish to care for their family member at home. Before we consider additional practices to support a greater uptake of, and engagement with, palliative care services on the part of Māori in particular, a brief consideration of the concept of culture is in order.

\section{DEFINING CULTURE}

Because of Aotearoa New Zealand's bicultural treaty, health care policy is centrally concerned with ethnic identity. Often, the effect is a description of culture in terms of ethnicity; this focus on ethnicity appears in the New Zealand Palliative Care Strategy (Ministry of Health, 2001). There may be a danger in such a narrow definition of culture. Nazroo (1999) argues that grouping people according to ethnicity allows explanations for health differences based on cultural stereotypes or assumptions about ethnic-based genetic differences. Stereotypes based on ethnic groupings, and assumptions made about genetic differences, are likely to result in discrimination and racism, which could lead to further ethnic inequalities in health care provision and must be addressed if we are to improve Māori health outcomes (Reid \& Robson, 2007).

A more useful approach that is not so easy to implement is to foster cultural competency in all health care workers so that every individual can have their cultural needs met (Megivern et al., 2007). For the purposes of this paper, the view of culture taken by the authors is similar to the view held by Alasuutari (1995, p. 25) who describes culture as a kind of "collective subjectivity, that is, a way of life or outlook adopted by a community or social class." This broader view of culture underpins the work of Outreach Care and significantly informs the model of practice utilized.

However, recent developments at Outreach Care embracing participatory community engagements have led us to question the idea that cultural competency in individual health workers is enough. ${ }^{6}$ Instead, what is required is organizational change that moves beyond Eurocentric individualism to a more collectivist approach to care. We now describe how this collectivist approach was developed.

${ }^{6}$ We thank an anonymous reviewer for this formulation. 


\section{CASE STUDY}

Grace was a 24-year-old Māori/Samoan woman who had been diagnosed with a brain tumor eighteen months before we met her. The tumor was fast growing and the most common and aggressive form of brain tumors in humans. Grace had undergone standard treatment (surgery, chemotherapy and radiotherapy) and was then referred to Outreach Care.

Our initial assessment was carried out with Grace and her whanau (extended family) on New Year's Eve 2009. This initial visit was lengthy, noisy, and in a small dark three-bedroom state house (government housing) that was shared by Grace, her mother, her brother, and her two young daughters. Access to the house was up a flight of concrete stairs that had no supportive railing.

We carried out a holistic assessment, which identified numerous issues, some physical, and many psychosocial (discussed shortly). Grace was wheelchair bound due to a dense left sided weakness (hemiplegia). She had cognitive impairment with consequent limitations in her ability for decision making, and she initially responded to questions with only very brief responses. These symptoms related to either raised intra cranial pressure or direct impingement of the tumor on brain structures.

Grace and her family faced many challenging psychosocial issues requiring involvement of an interdisciplinary team. At the time of our initial meeting the family was already in crisis. Her mother (Rata) was not coping with caring for Grace and her children while also trying to work for pay. They were struggling financially and Grace was in need of appropriate resources (equipment) that would assist in her care at home. Rata and her husband Sione were separated and Rata felt very alone in her care of Grace; she was struggling with meeting Grace's needs while also taking care of Grace's one- and three-year-old daughters. Rata spoke about her own parents being away on a mission as they were working for their church.

Grace's mother, who is Māori, and her father, who is Samoan, were soon able to work together to care for Grace. At times during her illness Grace felt safer being cared for by her father, as he could better manage her immobility issues given his physical size. There were times when lack of communication and tensions between her parents led to a breakdown in care arrangements. At times like this we would arrange or provide extra support.

Grace's house was inappropriate to meet the needs of someone in her condition, so we applied on her behalf to the government agency Housing New Zealand for a new and larger house. In addition, we made a referral to NASC (Needs Assessment Service Coordination) to assist with Grace's personal cares. We also utilized our hospice Health Care Assistant to meet this need until NASC had allocated someone.

${ }^{7}$ Grace and her whanau (extended family) have given permission for this case to be written up and are happy to have their story shared in this way. All names used are pseudonyms. 
During the first couple of months of our journey with this family, Grace had contact with our massage therapist and the art therapist, accessed spiritual support, and received on-going nursing and social work visits. In addition, Outreach Care provided regular food parcels for the family, as well as clothes for Grace from our hospice shops. At various times we held a meeting with the whanau/family to ascertain if the supports/resources that we had put in place were sufficient and functional. The result of the first of these meetings was a request for a respite admission to an IPU (in-patient unit hospice) for carer fatigue. This admission brought about Grace's initial meeting with the palliative care specialists who reviewed and altered her medications, which resulted in improvement in her overall symptomology.

In addition to these usual, if notably extensive, forms of support, a new initiative unfolded for the hospice during this time, which proved invaluable to Grace and her family. At the beginning of 2010, staff at the hospice began discussing the low number of referrals of Māori and Pacific people, and the significant number of these groups in our community. Grace often asked us: where are the other young Māori people who are sick? She spoke of the isolation she felt being so young and so sick. In response, in her role as the hospice social worker, Hughes worked alongside her manager to reach out to local Māori elders in the community and asked if they would meet with them. Hughes and her manager also asked for guidance from the Kaumatua (highly respected male Māori elder and leader) on the hospice board, as he was well-known in the local community. A meeting was held, during which the elders suggested that we hold a hui (gathering) and invite Māori as well as Pacific ethnic groups from the local community to come and tell us what they needed. We advertised the hui in local newspapers and informed all current Māori and Pacific patients and whanau/family about it. We had quite a lot of interest in the hui and the people who came suggested a weekly "drop in" at Outreach Care where people could gather and share their journey and experiences with others over a cup of tea.

The Māori/Pacific hui began to meet weekly, and gathered momentum quite quickly over the next few months. The formation of the hui group enabled us to obtain information from Māori and Pacific patients and families about what was required to best meet their needs as they navigated their journey through end-of-life care. Of central importance to the hui process is the Māori concept of whanaungatanga. This concept is about knowing you are not alone - that you have a wider group of people supporting, assisting, nurturing, and guiding you, with interdependence with each other, rather than independence, being the goal. Mead (2003) provides an explanation of whanaungatanga as the responsibility of whanau (extended family) to guide, support, and care for each other; it is a collective responsibility that comes from the practice of manaakitanga (the capacity to care-Drewery \& Bird, 2004). As whanau care for each other-manaaki each other-whanaungatanga is created and reinforced (Tangaere, 2012). As Tangaere emphasizes, whanaungatanga can extend beyond kin relationships, emerging from shared experiences.

Grace's Koro/grandfather came back to the city to support Rata in caring for Grace and he became the second Kaumatua who came every week to support the hui. We 
would arrange for transport to pick Grace up and bring her to the hui whenever she was well enough to attend, and she loved her time there. Responsibility for the running of the hui was assigned to the social worker (Hughes) by the agency. However, the hui was not run by one person. In developing the tikanga (procedure) for the hui, the group decided that the Kaumatua (Māori male elder/leader) would open the hui every week with a mihi (speech of greeting) and karakia (prayer), and that the other Kaumatua would then lead a waiata (song) prior to a round of sharing by all. Hughes and Cottle ( $\mathrm{RN}$ and co-author of this article) were perceived by the group to be equal participants in the hui and were therefore expected to join in the sharing and activities. At the same time, there was a certain amount of negotiation and background work required in their respective roles within Outreach Care to create and hold this collective space, which was much more interactive and informal than traditional agency protocol would allow. ${ }^{8}$

After a while, a nursing clinic was started alongside the hui so patients could be seen on a more regular basis (we discuss this initiative further in the next section of this paper). Our health care worker would also drop in when she could, as did other staff, the Family Services manager, and on occasion the CEO. The hui grew and flourished and soon encompassed people who were dying, family members whose loved ones were dying, Māori and Pacific family members who had been bereaved, and community workers. It became a key place for community workers to network with others and to find out what support was needed in the smaller ethnic groups in the community.

Grace's extended family would attend the hui with her, and would also attend when she was not well enough to come. At times, conflicts that had surfaced within Grace's whanau (extended family) were quickly mediated and resolved in the hui context. If there was quite personal conflict that was not appropriate to resolve in the hui as a whole, the Kaumatua (Māori male elder/leader) and the social worker (Hughes) would meet with those involved in a smaller group to discuss. The Kaumatua would provide a karakia (prayer) to start, and then hand over to Hughes to facilitate the conversation and an exploration of possible ways forward. Following Māori tikanga (procedure) and involving extended whanau in decisionmaking allowed for culturally attuned social work practice.

If Grace did not show for a hui, it would be a signal for us to initiate contact with her, which was often quite important and would not have otherwise occurred. Grace's family became very involved in the hui: her Koro (grandfather) became a hospice volunteer and has continued to support the hui on a weekly basis. Four generations of Grace's family attended our annual mother's day celebration (where they won the mother's day hamper!).

Over the remainder of 2010 our multi-systemic and wraparound care for Grace and her whanau continued, alongside her and her family's intensive involvement

${ }^{8}$ For instance, on one occasion Hughes used the Outreach Care van to take hui members to a hospital where a fellow hui participant was dying. Māori tikanga (procedure) was followed at the hospital, where karakia (prayer) and a round of speaking took place for the dying person and family members. Because of the time taken up by this process, the van was returned to Outreach Care well after business hours, and Hughes needed to account for this breach of the organization's standard procedures. 
in the hui they helped to inspire. We supported Grace to move to the new home we helped to secure, and then to residential care, while navigating an array of organizational, medical, and interpersonal challenges. These more traditional forms of support were quite important for Grace's care, and, it was clear that the hui context stood out for her as very significantly and uniquely valuable.

Grace became increasingly aware of the deaths of other patients in the hui group, and she became more aware that she would not get any better. She began to speak of this reality more often with all of the hospice staff. The hui also gave Grace the chance to hear other people's stories and to meet some younger Māori and Pacific women who were living with dying. The hui met Grace's need for companionship, understanding, and empathy, and helped to reduce her sense of isolation—at least for a period of time each week. This support was all provided within a cultural context that she loved, with her whanau (extended family) present, the sharing of food, the singing of waiata (songs), and with karakia (prayer) said by her Koro (grandfather) — who was one of the Kaumatua (Māori male elder/leaders) — as well as by the hospice Kaumatua. Grace died in early 2011.

\section{DISCUSSION}

We have often reflected on Grace's case as it was different from other patients' in many ways. Looking at her case from an ecological point of view it becomes clear that there were many systems that needed to be negotiated and taken into account in the process of caring for her. A "one size fits all" model of care was clearly not going to work in such a complex case, as a broader perspective of the needs was required. Locating Grace at the center of the systems, and seeing how many interacting systems were involved, was complex work. In total there were sixteen agencies involved in the care of Grace and her whanau/family. Contact with these agencies increased each time Grace hit a health crisis. Negotiating the interaction between systems, including the complex family systems, was time consuming and things could go wrong quite quickly if we were not fully up to speed with each agency. Clear and regular communication between all parties was vital to maintain the required level of care, and avoid cultural stereotypes and judgments that can occur when clients do not or cannot comply with standard institutionalized health care processes. Often, we (Hughes and Cottle) — in consultation with Grace-would bring a rich representation of Grace's life and her unique situation to health care specialists, in order to help contextualize for them the reasons why, for instance, a "young Māori woman" might have missed an oncology appointment.

The weekly hui greatly facilitated the integration of services, and also accomplished much more. By locating the Māori concept of whanaungatanga as central to Grace's care, and by bringing together a cultural community in partnership with health care professionals, Grace and her family were grounded in a larger and deeply supportive context for navigating their grieving and loss. They were invited to be 
part of a group (the hui) that advised and supported the hospice, while supporting one another, on the basis of cultural and community belonging. The participatory nature of the hui was important: in a more usual application of an ecological model, key cultural systems are taken into account, but in this case, a cultural community is helping to define the very terms and processes of care. Outreach Care's practices were significantly altered as a result of the hui: for instance, hui participants suggested following the principles of manakitanga (the capacity to care) by not only integrating, but also bringing together in one locality (the hui site) a range of service providers. One example was establishing a nursing clinic alongside hui meetings. As a result of this change, nursing clinic appointments often occurred spontaneously outside of scheduled clinic times, as part of hui processes. While such practices contravened official agency protocol of scheduled appointments, they helped to support hui members who were reluctant to attend formal clinic meetings. Additional changes in practice that came out of hui discussions included organizing for the massage therapist to teach massage techniques to family members, and bringing a cultural representative (volunteers from the hui) to initial assessments and home visits. All of these changes helped to de-individualize care.

Payne (2005) would argue that these community-based and participatory outcomes extend the usual parameters of an ecosystems approach to social work. He suggests that while an ecosystemic model can encourage social inclusion by inviting mutual help and community involvement-and can therefore increase people's capacity to influence their social situations-there is a tendency to accept and to integrate existing social systems. Change in systems can occur, but often it is small, or focused in the end on individual and family adaptation, not "systems" change. While it is true that an ecosystemic model assumes the interdependence of persons and their environments, and can therefore support change for social service workers and agencies, Payne argues that the Western European theoretical base of the model tends to be conservative by seeking "equilibrium" and "fit" across systems and between individuals and environments. In contrast, locating alternative cultural constructs such as whanaungatanga as a core element of care shifts the basis of meaning-making that is at work here. It begs the question: who defines and gives shape to the social environments we inhabit? Rather than promoting cultural competence, which relies on the figure of the informed, individual Western European health care worker, the Outreach Care hui enacted an alternative set of cultural practices within hospice care. As a result, the hui created the conditions for significant, not just incremental, change: for example, the gathering together and mutual support of many Māori and Pacific people who are living with dying, including young people who would otherwise be in relative isolation.

The hui encouraged an increased uptake of hospice support by Māori and Pacific people. As a result of the hui, for the first time, Māori and Pacific community organizations were directly linked with Outreach Care: representatives would drop by and take part in the hui, and would sometimes bring with them Māori and Pacific community members who were in need of hospice care but had been reluctant 
to agree to a referral. In addition, a sub-group of the hui developed to link with community events, to raise awareness of the availability of hospice care for Māori and Pacific people. In this capacity as volunteers for Outreach Care, hui members attended local events such as fairs and provided information about hospice and about the hui, which also served to increase Māori and Pacific engagement with Outreach Care. One of the Māori volunteers is currently training as a social worker with the goal of working in palliative care, an important and rare development.

\section{CONCLUSION}

The community approach to palliative care documented here is an example of bicultural health care and social work practice, which entailed transformative systems change. Outreach Care aimed not only to include, but also to mirror and enact the wishes, values, and understandings of minority cultural groups. ${ }^{9}$ Because Aotearoa New Zealand is a bicultural nation, such an approach to death and dying is uniquely fitting in this context, but there may be lessons here for palliative care in other social contexts as well.

Internationally, hospice care is carried out within a predominantly Western European health care system, and most care workers are White and middle-class. Within this scenario, there can be a default assumption that clients are (or should be) relatively well-resourced and individualized in their pursuit or uptake of care. It therefore requires deliberate intention on the part of relatively privileged care workers to create space for alternative cultural meanings and practices, and to support and defend that space as necessary within a larger social system that reflects a range of social inequalities. Palliative care workers everywhere can focus on decentering and questioning their own institutionally authorized power to construct the meaning of dying "for" others; in particular, they can recognize and challenge the silent, culturally dominant norm of death as a relatively individualized experience.

In thinking about Grace's case and what helped her in her struggle with the aloneness she felt (before the hui was established), we thought about the old adage that it takes a village to raise a child; in the same way it takes a village to care for the dying on their journey to the end of life. It took a whole village of grandparents, mums and dads, siblings, aunts and uncles, cousins and children, numerous hospice workers and community workers, the hui group, and sixteen agencies to care for Grace on her journey to the end of life. Although arguably dying is and will always be an intensely personal process that only the dying person can fully comprehend (Kuhl, 2002; Quill, 1991), this work demonstrates that the experience need not be individualized; rather, it can be held within a dynamic, responsive, and loving community of care. ${ }^{10}$

\footnotetext{
${ }^{9}$ An anonymous reviewer provided this phrasing.

${ }^{10}$ Note that the hui is still in place today. Undoubtedly the particular practices associated with it have shifted and will continue to shift over time, in accordance with the ideas and preferences of its fluctuating membership.
} 


\section{REFERENCES}

Alasuutari, P. (1995). Researching culture: Qualitative method and cultural studies. London: Sage.

Bellamy, G., \& Gott, M. (2013). What are the priorities for developing culturally appropriate palliative and end of life care for older people? The views of healthcare staff working in New Zealand. Health and Social Care in the Community, 1, 26-34.

Carter, H., McKinlay, E., Scott, I., Wise, D., \& MacLeod, R. (2002). Impact of a hospital palliative care service: Perspectives of the hospital staff. Journal of Palliative Care, $18,160-167$.

Cort, M. A. (2004). Cultural mistrust and use of hospice care: Challenges and remedies. Journal of Palliative Medicine, 7, 63-71.

Drewery, W., \& Bird, L. (2004). Human development in Aotearoa: A journey through life. (2nd ed.). Auckland, New Zealand: McGraw-Hill.

Durie, M. (2001). Whaiora: Māori health development (2nd ed.). Melbourne, Australia: Oxford University Press.

Finau, S., \& Tukuitonga, C. (1999). Pacific peoples in New Zealand. In P. Davis \& K. Dew (Eds.), Health and society in Aotearoa New Zealand (pp. 129-143). Melbourne, Australia: Oxford University Press.

Finlay, I., Higgenson, I., Goodwin, D., Cook, A., Edwards, A., Hood, K. et al. (2002). Palliative care in hospital, hospice, at home: Results from a systematic review. Annals of Oncology, 13, 257-264.

Germain, C. (1991). Human behaviour in the social environment: An ecological view. New York: Columbia University Press.

Heilig, S. (2003). Hospice with a Zen twist: A talk with Zen hospice founder Frank Ostaseki. Cambridge Quarterly of Healthcare Ethics, 12, 322-325.

Hughes, C. R., Fleming, T., Cottle, M., \& Davis, M. (2010, November). The delivery of culturally appropriate biopsychosocial care in the community: A challenge for specialist palliative care services. Paper presented at the 19th Hospice Palliative Care Conference, Wellington, New Zealand.

Karim, K., Bailey, M., \& Tunna, K. (2000). Nonwhite ethnicity and the provision of specialist palliative care services: factors affecting doctors' referral patterns. Palliative Medicine, 14, 471-478

Kuhl, D. (2002). What dying people want: Practical wisdom for the end of life. New York: Public Affairs.

Mackelprang, R. W., \& Mackelprang, R. D. (2005). Historical and contemporary issues in end-of-life decisions: Implications for social work. Social Work, 50, 315-324.

Massarotto, A., Carter, H., Macleod, R., \& Donaldson, N., (2000). Hospital referrals to a hospice: Timing of referrals, referrers' expectations, and the nature of referral information. Journal of Palliative Care, 16, 22-29.

Mead, H. M. (2003). Tikanga Māori: Living by Māori values. Wellington, New Zealand: Huia Publishers.

Megivern, D., McMillan, J., Enola, K., Striley, C., Cabassa, L., \& Munson, M. (2007). Quality of care: Expanding the social work dialogue. Social Work, 52, 115-124.

Ministry of Health. (2001). The New Zealand palliative care strategy. Wellington, New Zealand: Author. Retrieved January 18, 2013, from www.health.govt.nz/publication/ new-zealand-palliative-care-strategy 
Murray, A., Grant, E., Grant, A., \& Kendall, M. (2005). Dying from cancer in developed and developing countries: Lessons from two qualitative interview studies of patients and their carers. British Medical Journal, 326, 368-372.

Naylor, W. (2012). National health needs assessment for palliative care. Phase two report: Access to palliative care in New Zealand. Consultation document from the Palliative Care Council of New Zealand. Wellington: Cancer Control New Zealand. Retrieved January 20, 2013, from www.cancercontrolnz.govt.nz/sites/default/files/ HNA_Phase_2_Consultation_Draft_Report.pdf

Nazroo, J. Y. 1999. The racialization of ethnic inequalities in health. In D. Dorling \& S. Simpson (Eds.), Statistics in society: The arithmetic of politics (pp. 215-222). London: Arnold.

Payne, M. (2005). Modern social work theory (3rd ed.). New York: Palgrave Macmillan.

Pullis, B. (2011). Perceptions of hospice care among African Americans. Journal of Hospice and Palliative Nursing, 13, 281-287.

Quill, T. E. (1991). Sounding board, death and dignity: A case of individualized decision making. New England Journal of Medicine, 324, 691-694.

Reid, P., \& Robson, B. (2007). Understanding health inequities. In B. Robson, \& R. Harris (Eds.), Hauora: Māori standards of health IV: A study of the years 2000-2005 (pp. 3-10). Wellington, New Zealand: Te Ròpù Rangahau Hauora a Eru Pòmare.

Statistics New Zealand. (2006). Census of population and dwellings. Wellington, New Zealand: Author. Retrieved January 10, 2013, from www.stats.govt.nz/Census.aspx

Tangaere, A. R. (2012). A socio-cultural construction of Māori language development: Kohanga Reo and home. Unpublished doctoral dissertation, Auckland University. Retrieved February 3, 2013, from https://researchspace.auckland.ac.nz/docs/uoa-docs/rights.htm

von Gunten, C. (2002). Secondary and tertiary palliative care in U.S. hospitals. Journal of the American Medical Association, 287, 875-881. 
Copyright of Journal of Systemic Therapies is the property of Guilford Publications Inc. and its content may not be copied or emailed to multiple sites or posted to a listserv without the copyright holder's express written permission. However, users may print, download, or email articles for individual use. 